\title{
Stock Price Forecast Accuracy and Recommendation Profitability of Financial Magazines
}

\author{
Victor Tiberius *(D) and Laura Lisiecki \\ Faculty of Economics and Social Sciences, University of Potsdam, 14482 Potsdam, Germany; \\ laura.lisiecki@gmx.de \\ * Correspondence: tiberius@uni-potsdam.de
}

Received: 17 July 2019; Accepted: 19 September 2019; Published: 1 October 2019

\begin{abstract}
In this study, we analyze the forecast accuracy and profitability of buy recommendations published in five major German financial magazines for private households based on fundamental analysis. The results show a high average forecast accuracy but with a very high standard deviation, which indicates poor forecast accuracy with regard to individual stocks. The recommendation profitability slightly exceeds the performance of the MSCI World index. Considering the involved risk, which is represented by a high standard deviation, the excess returns appear to be insufficient.
\end{abstract}

Keywords: buy recommendations; financial magazines; forecast accuracy; MSCI World; recommendation profitability

JEL Classification: G11; G17

\section{Introduction}

Private households considering individual stocks for their personal financial investments are exposed to a plethora of possibilities. However, most of these investors lack the time, analytical skills, or even financial literacy (Gallery et al. 2011; Lusardi and Mitchell 2014) to select individual stocks professionally on their own. Financial magazines aimed at this target group regularly publish concrete buy recommendations, and by doing so, financial journalists publishing in these magazines undertake a task comparable to that of financial analysts or investment advisors.

In this paper, we analyze both the forecast accuracy and profitability of buy recommendations published in five major German financial magazines. Forecast accuracy is defined as the relative discrepancy between the published target price, interpreted as a stock price forecast, and the actual price at the end of the forecast horizon. Recommendation profitability is defined as the relative difference between the actual stock price at the date of recommendation and that at the end of the forecast horizon (Ertimur et al. 2007).

From a stockholder's perspective, forecast accuracy in and of itself is not of primary relevance, as the investor is not interested in precise forecasts but in highly profitable recommendations. A buy recommendation necessarily requires a positive difference between the current and expected future stock price. If the expected future stock price becomes a reality at the end of the forecast horizon, both the maximum forecast accuracy and the predicted recommendation profitability are achieved. If a difference between the current and the expected future stock price occurs, the actual recommendation profitability can be lower or higher than the expected one. The question of whether forecasted stock prices are accurate and whether buy recommendations are profitable is highly relevant for all private investors who base their investment decisions on buy recommendations from financial magazines.

Relatively little research has been conducted on financial forecast accuracy. The body of research focuses mainly on earnings forecasts rather than on stock price forecasts. Past earnings forecast 
accuracy is regarded as an important indicator for future forecast accuracy (Brown 2001), assuming that past forecast performance will continue. According to Hall and Tacon (2010), this assumption is justified because good forecasting ability appears to be persistent. Stickel (1992) found that members of the Institutional Investor All-America Research Team conduct more frequent forecasts and have better accuracy than other analysts. Analysts' forecasts are more accurate for companies located in industries in which they formerly worked (Bradley et al. 2017; Mikhail et al. 1999).

Several scholars have investigated analysts' recommendation profitability. For example, Bjerring et al. (1983) found that investors who followed the recommendations of a Canadian brokerage house would have gained above-market returns. Elton et al. (1986) and Desai et al. (2000) reached a similar conclusion. According to Ertimur et al. (2007), more accurate forecasts also produce higher profits than rough estimates. Other researchers suggest that there is no association between forecast accuracy and a recommendation's profitability (Hall and Tacon 2010; Mikhail et al. 1999). Positive forecasts and their resulting buy recommendations can lead to increased stock prices (Barber et al. 2006, 2010; Kerl and Walter 2007; Mathur and Wahed 1995; Womack 1996), thereby forming self-fulfilling prophecies as stock buyers increase their market demand and thereby raise stock prices. This case is especially true when herding occurs among financial analysts and buy recommendations are expressed by multiple analysts, suggesting a consensus among them (Clement and Tse 2005; Desai et al. 2000; Welch 2000). Forecast revisions lead to adjusted investment behavior by private investors, depending on prior forecast accuracy and other characteristics (Clement and Tse 2003). When the accuracy of prior forecasts is good, private investors expect the revised forecasts to be accurate and follow the new recommendations.

Even though stock prices are based on expected future earnings, other factors, such as the overall economic and sector-specific outlook, current interest rates, or disruptive threats by innovative competitors, also have an influence on stock prices. Thus, forecasting stock prices is more complex than forecasting future earnings alone because these other factors and their interdependencies must also be considered in the forecasts.

Even though relations between financial journalism and the stock market have been subject to some rare research (e.g., Ahern and Sosyura 2015; Douglas et al. 2012), only financial analysts' - not financial journalists' - forecasting accuracy and recommendation profitability have been considered by scholars so far. This salient research gap is remarkable, considering that thousands of explicit buy recommendations are published worldwide monthly and that these can have significant economic and social consequences for followers (Gallery et al. 2011).

\section{Data and Methodology}

The sample for this study consists of 554 buy recommendations published in the five major German financial magazines Börse Online (circulation: 24,540 copies in the fourth quarter 2016 ${ }^{1}$ ), Der Aktionär $(37,875)$, Euro am Sonntag (70,332), Focus Money (123,378), and WirtschaftsWoche $(135,394)$, between 7 December 2016 and 2 February 2017. The financial magazines covered stocks of large and second-line companies that have their registered headquarters in countries all over the world, so long as they are also listed on a German stock market.

The sample included only buy recommendations based on fundamental analysis. The magazines also published another 92 buy recommendations based on technical analysis. However, because only 19 of these recommendations mentioned a concrete target price, these were not included in the sample due to their lack of representativeness.

For the analysis, the corporation's name, the stock's International Securities Identification Number (ISIN), and the target stock prices were retrieved from the magazines. Additional information published by the magazines-e.g., fundamental data, such as the current or expected price-to-earnings (P/E) ratio,

1 Retrieved from the quarter circulation database at https://www.ivw.eu. 
the price-to-book $(\mathrm{P} / \mathrm{B})$ ratio, or dividend payout ratio and small verbal statements regarding past stock developments and its future outlook (e.g., based on its financial outlook and firm-level disclosures by the firms' Chief Financial Officers (CFO) (Hope 2003)) — was not part of the analysis.

Additionally, the actual stock prices on the publication date and after the end of the forecast horizon were retrieved from the online finance portal www.boerse.de to facilitate comparison with the target prices given in the recommendation. The time horizon was one year after publication, as confirmed by the magazines' chief editors in personal communication with the paper's second author. For chart-based forecasts, the time horizon was only three months, providing yet another reason to exclude them from the analysis. The time horizon of one year has the additional advantage that short-term market responses to buy recommendations do not become an issue in our analysis. Several studies found that stock prices are affected by published recommendations. For example, this finding was made by Lloyd-Davies and Canes (1978), who examined recommendations published after they had previously been disseminated to analysts' clients. The effect lasted for approximately 20 trading days. A similar observation was made by Beneish (1991) and Mathur and Wahed (1995), who examined published buy recommendations based on rumors or analysts' recommendations. They found a stock price increase one day before and two days after the publication date. Kerl and Walter (2007) found that price-pressure and information effects resulted in a stock price increase within five days of publication, especially for small stocks and glamour stocks. Such effects can be ignored using a long time horizon. The magnitude of the price change depends on the strength of the recommendation, the magnitude of the change in the recommendation, the reputation of the analyst, the size of the brokerage house, the size of the recommended firm, and simultaneous earnings forecast revisions (Stickel 1995).

Based on the gathered data, the following variables were calculated: the forecast error for each recommendation to buy the stock $s$ as

$$
F E_{s}=\frac{t s p_{t 1}-a s p_{t 1}}{t s p_{t 1}}
$$

where $t s p_{t 1}$ is the target stock price and asp $\mathrm{t}_{\mathrm{t} 1}$ is the actual stock price, both one year after publication of the recommendation $(t 1)$; the average forecast error for each magazine as

$$
F E_{m}=\frac{\sum_{n=i}^{k} F E_{s}}{k-i}
$$

where $i$ to $k$ is the range of stocks recommended in magazine $m$; the total average forecast error as

$$
F E=\frac{\sum_{1}^{N} F E_{s}}{N},
$$

where $N$ is the total number of all buy recommendations; the recommendation profitability for each buy recommendation as

$$
R P_{s}=\frac{a s p_{t 1}-a s p_{t 0}}{a s p_{t 0}}
$$

where $a s p_{t 0}$ is the actual stock price at the date of the publication (t0); the average recommendation profitability for each magazine as

$$
R P_{m}=\frac{\sum_{i}^{k} R P_{s}}{k-i}
$$

and the total average recommendation profitability as

$$
R P=\frac{\sum_{1}^{n} R P_{s}}{n} .
$$

For simplicity, transaction costs were not considered. Only buy rather than sell recommendations were included in the sample because sell recommendations were rarely published by the magazines 
and, due to missing prior buy information (buy date $t-1$ and price $s p_{t-1}$ ), neither forecast accuracy nor recommendation profitability could have been calculated.

\section{Results}

For all 554 buy recommendations, the average forecast error was +0.0095 , which indicates a very high overall forecast accuracy. However, the standard deviation was 0.3287 , which indicates that the forecast accuracy for individual stocks was rather poor. Figure 1 shows the distribution of the forecast error around its average value $(+0.0095)$.

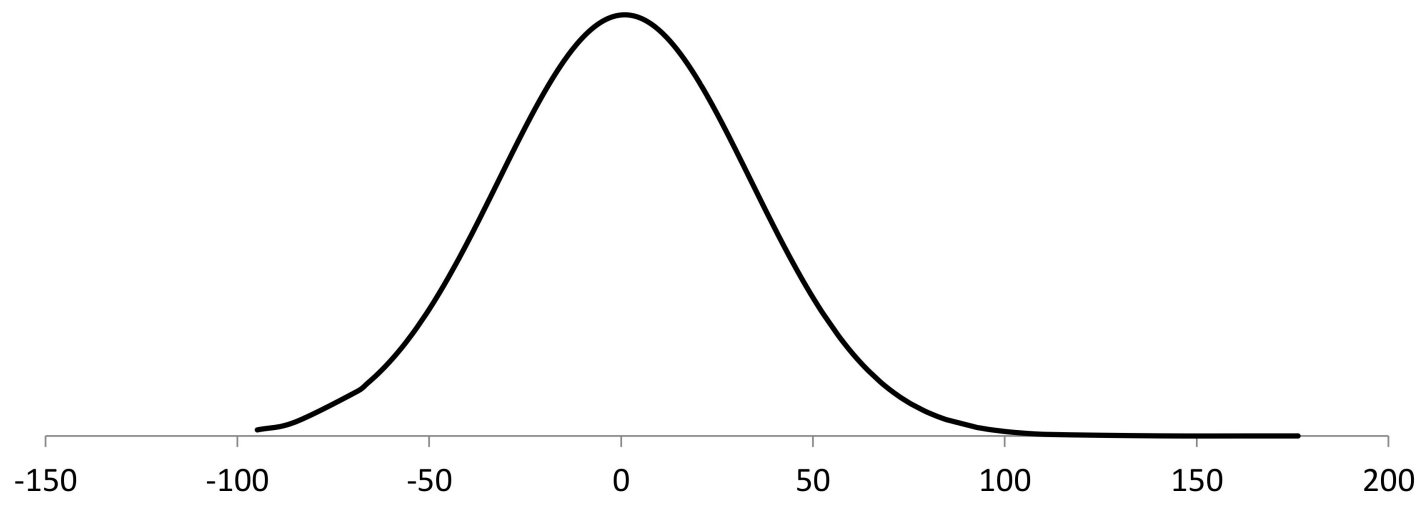

Figure 1. Distribution of the forecast error.

The most accurate forecast was for Palfinger AG, which had a discrepancy of 0.0000 for both the target and actual prices one year after publication, exactly 36.00 Euros each. The highest negative forecast discrepancy was -0.9481 for the stock of Steinhoff International Holdings NV, which crashed because of an accounting scandal that was unanticipated by the financial journalist and the market in general. The highest positive forecast discrepancy was +1.7644 for Siltronic AG.

The average recommendation profitability of all 554 buy recommendations was 0.2745 per year, which is an attractive overall return. Financial journalists generated an attractive alpha compared to the highly diversified MSCI World index, which increased from 5334.630 on 7 December 2017, to 6273.35 on 6 December 2018, an increase of 0.1820 .

However, the recommendation profitabilities for individual stocks were greatly scattered again. The highest profit was +2.9563 for Aixtron SE, and the highest loss was -0.9360 for Steinhoff International Holdings NV. Of all buy recommendations, 0.2184 led to a loss, in congruence with Mathur and Wahed (1995) findings that long-term investors earn below market rates of return when following secondary information, such as buy recommendations published in financial magazines, based on rumors or financial analysts' prior buy recommendations. Similarly, Palmon et al. (2009) found that investors who followed financial magazines' columnists' recommendations would not have received abnormal returns.

The results for each magazine can be found in Table 1. The representativeness of the results of WirtschaftsWoche is limited, as the magazine contained only 10 forecasts. However, we included the magazine due to its high circulation. 
Table 1. Results for each magazine.

\begin{tabular}{|c|c|c|c|c|c|c|}
\hline Magazine & $\begin{array}{c}\text { Börse } \\
\text { Online }\end{array}$ & $\begin{array}{c}\text { Der } \\
\text { Aktionär }\end{array}$ & $\begin{array}{l}\text { Euro am } \\
\text { Sonntag }\end{array}$ & $\begin{array}{l}\text { Focus } \\
\text { Money }\end{array}$ & Wirtschafts-Woche & Overall \\
\hline \multicolumn{7}{|c|}{ Forecast error } \\
\hline $\mathrm{FE}$ & 0.0342 & 0.0016 & -0.0136 & 0.0213 & 0.0594 & 0.0095 \\
\hline Standard deviation (SD) of FE & 0.3144 & 0.3657 & 0.2179 & 0.2768 & 0.5604 & 0.3287 \\
\hline Highest negative $\mathrm{FE}_{\mathrm{s}}$ & -0.6383 & -0.8500 & -0.4870 & -0.5330 & -0.9481 & -0.9481 \\
\hline Highest positive $\mathrm{FE}_{\mathrm{s}}$ & 1.1100 & 1.7644 & 0.4939 & 0.8486 & 0.7569 & 1.7644 \\
\hline Smallest $\mathrm{FE}_{\mathrm{S}}$ & 0.0000 & 0.0054 & 0.0047 & 0.0012 & 0.0021 & 0.0000 \\
\hline \multicolumn{7}{|c|}{ Recommendation profitability } \\
\hline $\mathrm{RP}$ & 0.2907 & 0.3022 & 0.1515 & 0.2871 & 0.2408 & 0.2745 \\
\hline Maximum profit & 2.9563 & 2.2228 & 0.7995 & 2.2320 & 1.3276 & 2.9563 \\
\hline Maximum loss & -0.5751 & -0.6727 & -0.3677 & -0.3655 & -0.9360 & -0.9360 \\
\hline $\begin{array}{l}\text { Percentage of loss-generating } \\
\text { recommendations }\end{array}$ & 0.2229 & 0.3760 & 0.2000 & 0.1896 & 0.4000 & 0.2960 \\
\hline
\end{tabular}

\section{Discussion}

\subsection{Assumptions}

The analysis is based on a number of assumptions. First, it is assumed that a virtual investor builds a portfolio that represents all given buy recommendations. Because readers of financial magazines usually do not follow all given buy recommendations, individual portfolios will be realized and will have different performances. Second, it is assumed that exactly the same amount is invested in every recommended stock because the financial magazines recommend only which stocks to buy but obviously not how much money to invest. However, an equal allocation of stocks in the portfolio is neither sensible nor possible due to different prices for different stocks. Third, it is assumed that readers buy the recommended stocks on publication day and sell them exactly one year later. Again, this assumption is unrealistic because individual readers can buy stocks later and sell them before or after the forecast horizon ends. Thus, the financial magazines' portfolios are a theoretical construct rather than a real phenomenon. However, in this restrictive way, the analysis is legitimate because these parameters are immanent to the financial magazine design: They give more buy recommendations than a usual reader can follow, they do not give concrete recommendations on the weighing of the stocks in the portfolio, they appear on a certain publishing date, and the defined time horizon for the forecasts is one year.

\subsection{Risk Adjustment}

Because portfolio management should always be related to both return and risk, a solely profitability-oriented view on magazines' buy recommendations would obscure equally important risk considerations. There are different measures for risk-adjusted return. For example, the prominent Sharpe (1994) ratio measures the return per unit of deviation in the portfolio, or concretely, it is the relation between the value of the excess of the asset return over the benchmark return (usually government bonds considered riskless) and the standard deviation of the asset excess return (usually the portfolio's volatility). In a loose analogy to this measure, a risk-adjusted perspective on the financial magazines' excess return can be calculated as

$$
R P_{\text {riskadj }}=\frac{R P-R_{\text {index }}}{\mathrm{SD}}=0.2814
$$

The return of the MSCI World index $\left(R_{\text {index }}\right)$ for the period of one year after the first buy recommendation cannot be interpreted as a risk-free rate but as a legitimate benchmark return that stockholders might have gained by investing in a highly diversified exchange-traded fund (ETF) that represents the 1649 stocks of this index worldwide. The difference between the recommendation profitability of the magazines $\left(R D_{m}\right)$ and the return of the MSCI World index $\left(R_{\text {index }}\right)$ has to be considered in relation to the standard deviation of the forecast errors (SD), analogous to the volatility of a portfolio. A ratio of 1.000 would suggest an even relation between return and risk. The actual ratio of 0.2814 
suggests that the relation of excess return compared to the MSCI World index, in relation to forecast errors, is too high.

Another method to evaluate the risk-adjusted returns of the buy recommendations is to compare the magazine-specific Sharpe ratios,

$$
S R_{m}=\frac{R P_{m}}{S D_{m}}
$$

with the Sharpe ratio of the MSCI World index

$$
S R_{\text {index }}=\frac{R P_{\text {index }}}{S D_{\text {index }}}
$$

In both cases, we dispense with the subtraction of the risk-free interest rate in the numerator because it is currently approximately zero (e.g., slightly negative in Europe and slightly positive in the U.S.). The Sharpe ratios are depicted in Table 2. The values show very good risk-adjusted returns for Focus Money and for Börse Online. However, the Sharpe ratio of the MSCI World index is much higher.

Table 2. Sharpe ratios of magazines and MSCI World index.

\begin{tabular}{ccccccc}
\hline $\begin{array}{c}\text { Börse } \\
\text { Online }\end{array}$ & $\begin{array}{c}\text { Der } \\
\text { Aktionär }\end{array}$ & $\begin{array}{c}\text { Euro am } \\
\text { Sonntag }\end{array}$ & $\begin{array}{c}\text { Focus } \\
\text { Money }\end{array}$ & Wirtschafts-Woche $\begin{array}{c}\text { All } \\
\text { Magazines }\end{array}$ & $\begin{array}{c}\text { MSCI } \\
\text { World }\end{array}$ \\
\hline 0.9246 & 0.8264 & 0.6953 & 1.037 & 0.4297 & 0.8351 & 4.008 \\
\hline
\end{tabular}

\section{Conclusions}

From a pure forecasting perspective, finance magazines are highly accurate on average but with a high standard deviation. Thus, financial journalists' forecast accuracy for individual stocks was rather poor.

Stockholders who would have followed all buy recommendations would have generated an excess profit compared to that of the broader stock market. This outcome is consistent with findings suggesting that analysts prefer to pick high momentum and growth stocks (Jegadeesh et al. 2004), especially high-tech stocks (Kwon 2002) that have outperformed in recent years. However, considering the high error rate of buy recommendations leading to high losses, following all buy recommendations can only be suggested for investors with an above-average risk appetite. Two risk-adjusted perspectives relating the returns to the MSCI World index performance and Sharpe ratios confirm this finding.

\section{Limitations and Future Research}

The study has several limitations. First and foremost, the data stem from a rather short, three-month period. For a preliminary study such as this, the insights are interesting. However, future studies should include longer periods. Second, the study covered a long bull market phase. Picking stocks and forecasting rising stock prices appears to be easier during such phases rather than in bear or highly volatile markets. Future research should also examine forecast accuracies and recommendation profitabilities in bear or more volatile markets. We expect that both forecast accuracy and recommendation profitability would suffer in such markets. However, Sharpe ratio comparisons with the MSCI World index would also show completely different results. For example, its return one year later (7 December 2017, to 6 December 2018) was -0.0123, and the Sharpe ratio was only 0.4457. Third, only German financial magazines were studied. To preclude a national or cultural bias, financial magazines from other countries should also be examined. Fourth, forecasts depend not only on forecasters' characteristics (Brown 2001; Clement and Tse 2003) but also on their forecast methods. This study focused on forecasts based on fundamental analyses alone. Future studies should also consider covering other sources, such as recommendations based on technical analysis and sentiment analysis. Fifth, future studies might also cover other underlying elements besides stocks, e.g., commodity prices, bond prices, or currencies. 
Author Contributions: V.T. and L.L. jointly developed the study design. L.L. conducted the study. V.T. and L.L. jointly analyzed the data. V.T. wrote the first draft and revised paper. L.L. edited the revision.

Funding: The APF was funded by the Deutsche Forschungsgemeinschaft (DFG) and the Open Access Publishing Fund of University of Potsdam. We gratefully acknowledge their support.

Conflicts of Interest: The authors declare no conflict of interest.

\section{References}

Ahern, Kenneth R., and Denis Sosyura. 2015. Rumor Has It: Sensationalism in Financial Media. Review of Financial Studies 28: 2050-93. [CrossRef]

Barber, Brad M., Reuven Lehavy, Maureen McNichols, and Brett Trueman. 2006. Buys, holds, \& sells: The distribution of investment banks' stock ratings \& the implications for the profitability of analysts' recommendations. Journal of Accounting \& Economics 41: 87-117. [CrossRef]

Barber, Brad M., Reuven Lehavy, and Brett Trueman. 2010. Ratings Changes, Ratings Levels, \& the Predictive Value of Analysts' Recommendations. Financial Management 39: 533-53. [CrossRef]

Beneish, Messod D. 1991. Stock Prices and the Dissemnation of Analysts' Recommendations. Journal of Business 64: 393-416. [CrossRef]

Bjerring, James H., Josef Lakonishok, and Theo Vermaelen. 1983. Stock prices and financial analysts' recommendations. Journal of Finance 38: 187-204. [CrossRef]

Bradley, Daniel, Sinan Gokkaya, and Xi Liu. 2017. Before an Analyst Becomes an Analyst: Does Industry Experience Matter? Journal of Finance 72: 751-91. [CrossRef]

Brown, Lawrence D. 2001. How important Is Past Analyst Forecast Accuracy? Financial Analysts Journal 57: 44-49. [CrossRef]

Clement, Michael B., and Senyo Y. Tse. 2003. Do Investors Respond to Analysts' Forecast Revisions as if Forecast Accuracy Is All That Matters? Accounting Review 78: 227-49. [CrossRef]

Clement, Michal B., and Senyo Y. Tse. 2005. Financial Analyst Characteristics \& Herding Behavior in Forecasting. Journal of Finance 60: 307-41. [CrossRef]

Desai, Hemang, Ding Liang, and Ajai K. Singh. 2000. Do All-Stars Shine? Evaluation of Analyst Recommendations. Financial Analysts Journal 56: 20-49. [CrossRef]

Douglas, Casey, Joseph Engelberg, Diego García, and Christopher Alan Parsons. 2012. Journalists and the Stock Market. Review of Financial Studies 25: 639-79. [CrossRef]

Elton, Edwin J., Martin J. Gruber, and Seth Grossman. 1986. Discrete expectational data and portfolio performance. Journal of Finance 41: 699-713. [CrossRef]

Ertimur, Yonca, Jayanthi Sunder, and Shyam V. Sunder. 2007. Measure for Measure: The Relation between Forecast Accuracy and Recommendation Profitability of Analysts. Journal of Accounting Research 45: 567-606. [CrossRef]

Gallery, Natalie, Cameron Newton, and Chrisann Palm. 2011. Framework for assessing financial literacy and superannuation investment choice decisions. Australasian Accounting, Business and Finance Journal 5: 3-22.

Hall, Jason L., and Paul B. Tacon. 2010. Forecast accuracy and stock recommendations. Journal of Contemporary Accounting \& Economics 6: 18-33. [CrossRef]

Hope, Ole-Kistian. 2003. Disclosure Practices, Enforcement of Accounting Standards, \& Analysts' Forecast Accuracy: An International Study. Journal of Accounting Research 41: 235-72. [CrossRef]

Jegadeesh, Narasimhan, Joonghyuk Kim, Susan D. Krische, and Charles M. C. Lee. 2004. Analyzing the Analysts: When Do Recommendations Add Value? Journal of Finance 59: 1083-124. [CrossRef]

Kerl, Alexander G., and Andreas Walter. 2007. Market Responses to Buy Recommendations Issued by Personal Finance Magazines: Effects of Information, Price-Pressure, and Company Characteristics. Review of Finance 11: 117-41. [CrossRef]

Kwon, Sung S. 2002. Financial Analysts' Forecast Accuracy \& Dispersion: High-Tech versus Low-Tech Stocks. Review of Quantitative Finance \& Accounting 19: 65-91. [CrossRef]

Lloyd-Davies, Peter, and Michael Canes. 1978. Stock prices and the publication of second-hand information. The Journal of Business 51: 43-56. [CrossRef]

Lusardi, Annamaria, and Olivia S. Mitchell. 2014. The Economic Importance of Financial Literacy: Theory and Evidence. Journal of Economic Literature 52: 5-44. [CrossRef] [PubMed] 
Mathur, Ike, and Amjad Wahed. 1995. Stock price reactions to securities recommended in business week's "Inside Wall Street". Financial Review 30: 583-604. [CrossRef]

Mikhail, Michael B., Beverly R. Walther, and Richard H. Willis. 1999. Does Forecast Accuracy Matter to Security Analysts? Accounting Review 74: 185-200. [CrossRef]

Palmon, Dan, Ephraim F. Sudit, and Ari Yezegel. 2009. The value of columnists' stock recommendations: An event study approach. Review of Quantitative Finance and Accounting 33: 209-32. [CrossRef]

Sharpe, William F. 1994. The Sharpe Ratio. Journal of Portfolio Management 21: 49-58. [CrossRef]

Stickel, Scott E. 1992. Reputation \& Performance Among Security Analysts. Journal of Finance 47: 1811-36. [CrossRef]

Stickel, Scott E. 1995. The Anatomy of the Performance of Buy and Sell Recommendations. Financial Analysts Journal 51: 25-39. [CrossRef]

Welch, Ivo. 2000. Herding among security analysts. Journal of Financial Economics 58: 369-96. [CrossRef]

Womack, Kent L. 1996. Do brokerage analysts' recommendations have investment value? Journal of Finance 51: 137-67. [CrossRef]

(C) 2019 by the authors. Licensee MDPI, Basel, Switzerland. This article is an open access article distributed under the terms and conditions of the Creative Commons Attribution (CC BY) license (http://creativecommons.org/licenses/by/4.0/). 